\title{
New Interactive Simulator to Mimic Kick Behavior in Wells of Southern Iraqi fields
}

\author{
Ameer Ali Hussein, Dr. Mohammed Saleh Aljawad \\ Petroleum Technology Department / University of Technology
}

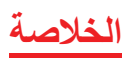

الفرق غير المتأهبة او غير الخبيرة بالتعامل مع مشاكل الحفر التي تحصل داخل البئر، في حالة مواجهة ابي مشكله مفاجئة خلال العمل من الممكن ان تؤدي الى اصابات خطيرة، مشاكل بيئية و خسائر مالية كبيرة. لهذا السبب، نم البدا بتطوير محاكاة الحفر و استخدامها بالتعليم و التدريب. عادة يتم التركيز على اخطر مشاكل الحفر على الكادر و اكثرها تكلفة مثل: الرفسة، خسائر الطين و استعصاء الانابيب.

التدريب و التعليم يكون بافضل حالاته عندما يكون مرتبط بحالات حقيقيه، لهذا السبب تقنيات حديثة تم تعريفها و استخدامها في هذا

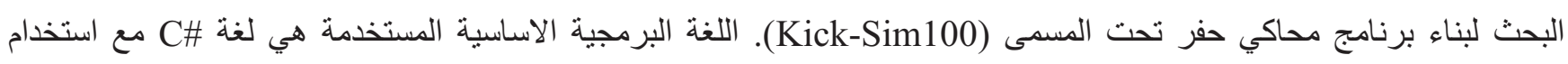

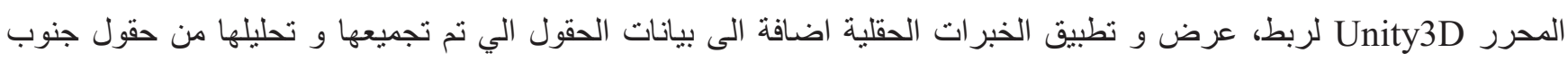
العراق.

(Kick-Sim100) الاكثر شيوعا من طرق السيطرة على البئر، طريقة الحفار و طريقة المهند. المحاكي يتعامل مع طبقات العراق الجنوبية و ايضا لئاء

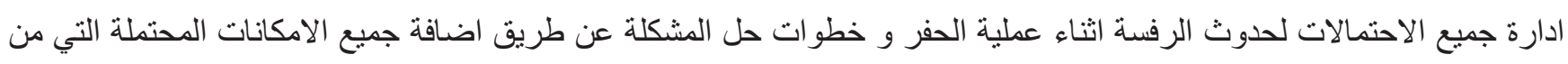
المككن ان تحدث اثناء عملية قتل البئر و بصورة تلقائية، و بدون الحاجة الى تدخل اي مرشد.

من المتوقع ان يكون للبرنامج (Kick-Sim100) تاثير كبير على تحسين قدرات كادر الحفر بالتعامل مع الرفسة و اكتشافها و طرق

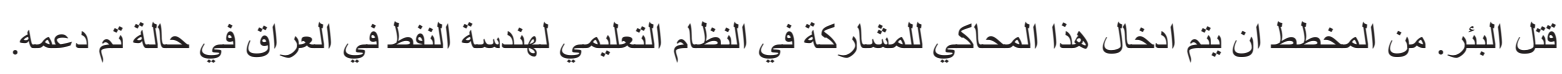

\section{$\underline{\text { Abstract }}$}

An unprepared drilling team or an inexperienced group in dealing with bottom hole drilling problems can cause serious injury, health troubles, environmental damage and rigorous financial losses for any contingency hole troubles that might be faced during the drilling progress. For that reason, drilling simulators have been developed and used in teaching and training, usually in well control, focusing on how to handle the most dangerous and expensive problems such as kicks, mud losses, and stuck pipes.

It is believed that the practice preferred to be related to real cases for best results, so modern techniques have been introduced in this research to build anew drilling simulator software under the name "KickSim100". The main programming language used is C\# language and Unity3D editor used as a 
programming environment, together used to connect, exhibit and implement field experiences and field data that gathered and analyzed from southern Iraqi fields.

Kick-Sim100 imitates the behavior of the kick for both types: gas and water kick. It also mimics two of the most common well control methods, namely the "Driller" method and the "wait and weight" method. This simulator deals with southern Iraqi formations also manages the possibilities of kick occurrence and problems solving steps by involving all the potential odds that might arise during well killing procedures automatically, in which It does not need any instructor involvement.

Kick-Sim100 is expected to have a great impact on the improvement of the drilling staff abilities in handling kick detection while drilling and well-killing methods. It is also planned to participate in Iraqi petroleum engineering educational systems in the future if developed.

\section{Introduction}

A Simulator is defined as a device or a software that is used to reproduce a physical behavior in some degree of exactness. In petroleum industry simulators are widely used in many aspects especially in drilling operations and reservoir modeling. Drilling operation is one of the most expensive operations in the petroleum industry. Kick is one of the most dangerous problems in drilling operation that may escalate to a blowout. Drilling staff experience is one of the most important factors that directly affects the ability of the staff to handle any of the down hole problems especially dangerous problems such as kick.

In this paper, anew drilling simulator software that concerns with kick problem and kick solving procedures has been developed under the name (Kick-Sim100) to simulate the kick behavior and well killing procedures in vertical wells. (Kick-Sim100) built based on data and information that are collected and gathered from Iraqi fields. Using drilling simulators have been proven to be one of the best ways that used for training and have a great impact on the experience and handling ability of drilling teams.

This paper is based on data and information that gathered from southern Iraqi fields that distributed mainly in Basra, Missan, and Nasiriya. The fields that covered are the following:

1. Rumaila Oil Field: The field is found $50 \mathrm{~km}$ toward the west of the city of Basra, southern Iraq, and some $30 \mathrm{~km}$ to the west of the Zubair field. [1] 
2. Zubair Oil Field: This is an oil field located in southern Iraq, approximately $20 \mathrm{~km}$ south-west of Basra. [2]

3. West Qurna 1 Oil Field: It is an oil field, located $50 \mathrm{~km}$ northwest of the city of Basra, and overlaps the northern edge of the Rumaila field. [3]

4. West Qurna 2 Oil Field: It is situated in the southern Iraqi part, 65 kilometers north-west of Basra, and it is one of the world's largest fields. [4]

5. Nasiriya Oil Field: It is located in the southern of Iraq, in Thi-Qar province (close to Nasiriya city). [5]

6. Gharraf Oil Field: This field is situated in southern Iraq, in Thi-Qar governorate. It has a dimension that is aligned in NW-SE direction of $10 \mathrm{~km}$ in width and $31 \mathrm{~km}$ in length. [6]

7. Halfaya Oil Field: is a giant oil field, located east of Amarah, Iraq. It is located at some $400 \mathrm{~km}$ south east of Baghdad. [7]

8. Buzurgan Oil Field: is located in the South -Eastern part of the Republic of Iraq, close to the Iran boundary, $40 \mathrm{Km}$ North East of Amara. [8]

9. Noor Oil Field: is one of the smallest fields in Missan province discovered in late of 1973, the direction of Noor oil field's axis is similar to the axes of neighboring structures, north westsouth east. [9]

10. Fauqi Oil Field: Fauqi Oil Field has an axial length about $26 \mathrm{~km}$ and its width is about $6 \mathrm{~km}$ with these coordinates (3554000-3565000) northing lines and (737000-743000) easting lines. [10]

\section{$\underline{\text { Kick analysis }}$}

The kick is one of the most dangerous downhole problems because of its relation to staff safety. To mimic the behavior of the kick during the occurrence and the solving procedures accurately, the physical forces in the downhole should be fully understood. This problem will be discussed in many parts and as follows:

\section{Kick occurrence}

When a certain amount of formation fluid enters the well, a kick is formed. The kick could occur only in permeable formations with a fluid (gas or water) in it. The kick occurs if the driller failed to maintain proper hydrostatic pressure (due to human error or some other external circumstances).

Formation fluids have densities less than drilling mud. If a kick takes place, the hydrostatic pressure will decrease as a result of the kick entering which occupies a portion in the mud column, and as the 
amount of the kick increases, the hydrostatic pressure will decrease simultaneously. This continuous decrease in the hydrostatic pressure will increase the severity of the kick and the chances to escalate to a blowout.

The amount of the hydrostatic pressure drop due to kick entrance depends on the density of the fluid that formed the kick and the amount of the kick (the kick amount will affect the height of the kick column in the annulus).

The Hydrostatic pressure of the fluid column in the annulus can be represented by the following equation:

$$
P H=0.052 *\{(\rho \operatorname{mud} * \operatorname{TVD})-(\rho \operatorname{mud} * h \inf .)+(\rho \inf \operatorname{lux} * h \text { inf. } .)\} \ldots \ldots(1)
$$

As $\rho$ influx is always less than $\rho$ mud, Term A will always be greater than Term B. as the parameters ( $\rho$ influx, $\rho$ mud and TVD) are constant for each problem case when the problem occurs, the main affected factor is the influx height. Term $\mathrm{A}$ is a negative value and the Term B is a positive value, and from the mathematical point of view, any increase in the influx height has a greater impact on Term A than Term B because the density of the mud is always higher than influx density. As a result of these two points, any increase in the influx height decreases the hydrostatic pressure.

\section{Kick treatment}

The Driller's method and the Engineer's method are the most common well control methods used in Iraqi fields, so they will be analyzed in details to be inserted to the software. The correct solving steps will be studied to match them with the steps in the simulator. The most important part of the kick analysis is the effect of the incorrect decisions that might happen during solving the problem.

\section{$\underline{2.1 \text { Driller's method }}$}

The main feature of the driller's method is killing the well with two steps. Each step requires certain parameters and a united procedure. If the driller failed to supply the right values of the required parameters, the problem may escalate and add more complexity to the case.

\section{A. First circulation}

This step concerns with circulating the kick with the original mud. To proceed correctly through the first circulation, correct (ICP) value is needed to control the formation pressure through the process. 
This step succeeds if the correct value of the ICP is used and the pressure within the downhole is handled correctly using the choke line. ICP should be analyzed to understand the effect of using different ICP values on the solving process, ICP is represented in the equation (2):

$I C P=S I D P P+K R P$

As long as the initial circulating pressure is higher than the KRP, the circulation can take place. SIDPP value is equivalent to the pressure difference between formation pressure and hydrostatic pressure. As a result, if a circulation needs to be established, the circulating pressure should be equal or higher than KRP and to make a balance between the well and the formation pressure, the SIDPP value should be added to the KRP to make the circulation and make a balance in the well.

Using pump pressure less than KRP instead of ICP, the circulating will be impossible to take place as the pump pressure is less than the minimum pressure required to overcome the friction in the well. And in this case another kick will enter the well because of the lack of the pressure in the well to balance the pressure in the downhole while circulating.

If the used pump pressure is higher than KRP and lower than ICP, the circulation will be initiated as the minimum pressure required to circulating the mud is met but the pump pressure won't be enough to maintain the balance in the downhole and a new kick is expected to enter the well.

If the used pump pressure is higher than ICP, the circulation will be initiated as the pressure is higher than the KRP. The formation fluids will be blocked as the Pressure in the downhole is higher than the correct ICP, but if the pressure in the downhole exceeds the formation fracture pressure, a fracture will occur and the well might be lost.

To understand the choke principles in the first circulation, the first circulation will be divided into two stages to be understood fully. For the first stage, the driller should operate the pump then increase the pump pressure gradually to the correct ICP and open the choke step by step in order to keep the casing pressure steady by handling the choke correctly.

In general, the choke acts based on Bernoulli's equations and it can be described how Bernoulli's equations affect the choke in a very simple way. The choke is placed on the choke line that is diverted from the BOP, if the choke is closed, the pressure in the line will be at the maximum value, while if the choke is fully opened, the pressure in the line will be at the minimum value and if the choke is partially opened, the pressure in the line will be at a mid-value. 
The pump enters a new pressure to the system (bottom hole), so the pressure will be increased and that may form a fracture, and in order to maintain the pressure stable in the downhole, the choke should be adjusted carefully.

In the first stage of the first circulating the driller operates the mud pump, increase the pressure to ICP and open the choke gradually. The driller should manage the choke opening carefully and keep the casing pressure stable to avoid any escalation. But if the driller stops adjusting the choke and keeps it with a small opening, the pump pressure will be trapped in the system. In this situation, if the pressure in the casing exceeds the fracture pressure of the formation, an underground blowout will occur.

If the driller opens the choke more than the right opening amount, the pressure within the borehole escapes from the choke line and the pressure in the casing will be dropped, and this leads to an unbalanced forces summation in the downhole and a new kick may enter the well. The kick may be escalated to a blowout may, if the pressure difference between the formation and the downhole is too high.

For the second stage which begins after the pump pressure reaches the initial circulation pressure (ICP), the driller should maintain the pump pressure constant at (ICP) by adjusting the choke opening. If the driller failed to maintain the pump pressure at (ICP), another kick or fracture may take place depends on the pressure state. If the pressure dropped below the (ICP) because of the wrong choke adjustment, a new kick will enter the well. If the pressure raised above the (ICP) because of the wrong choke adjustment, an underground blowout may take place if the downhole pressure exceeds the fracture pressure of the formation.

In the second stage, if the kick type is water, the casing pressure will be constant as the driller control the choke correctly keeping the drill pipe pressure at (ICP). If the kick type is gas, the casing pressure will be raised as the kick goes up, even if the driller keeps the drill pipe pressure at (ICP). To describe the cause of the change in the casing pressure, the distribution of the forces in the annulus needs to be understood. There are two forces acting in the annulus, the downward force implemented by the summation of the hydrostatic pressures caused by the liquid column of the kick and the column of the original mud, and the upward force implemented by the pump pressure. The summation of the forces changes continuously as the kick rises because of the kick expansion which reduces the hydrostatic summation and that reduction causes the increase in the force summation in the upward direction in the annulus and increase the casing pressure gauge. 
The casing pressure will drop after the kick leaves of the annulus. This drop is caused as the result of the hydrostatic pressure increase in the annulus (the force downward is increased) because the hydrostatic pressure of the mud only is higher than the hydrostatic pressure of the summation of the gas and mud columns, and this leads to reduction in the summation of the forces in the upward direction.

After the kick exits the well, If the recorded SICP and SIDPP are unequal, then there is something went wrong in the first circulation. Either a new kick enters the well or some portion of the original kick remains sealed in the annulus, and makes the hydrostatic pressure in the annulus lower than the hydrostatic pressure in the drill string due to the existence of some of the gas kick with low density in the annulus. As the upper direction forces caused by the formation are equal in the annulus and in the drill string, the summation of the forces in the upper direction in the annulus will be higher.

\section{B. Second circulation}

In this circulation, KMW should be prepared, also FCP and STB should be calculated to be used in this circulation. To describe the physical behavior of the second circulation, it is divided into two stages.

In the first stage, the new mud is initially pumped by raising the pump pressure to ICP, then the driller should decrease the pressure in the drill string gradually to reach the FCP at the point where the new mud reaches the bit, by adjusting the choke opening. To understand the importance of decreasing the drill pipe pressure to FCP and what may happen if the driller keeps the drill pipe pressure at ICP, the forces in the downhole should be analyzed. At the beginning of the second circulation, ICP should be implemented in order to circulate the mud and control the formation pressure as in the previous sections, but as the new mud which is heavier than the original mud enters the drill string which implements an extra hydrostatic pressure, pump pressure should be decreased gradually in a way that keeps the casing pressure constant by choke adjustment to prevent any escalation in the case.

The second stage of this circulation begins after the mud reaches the bit and flows into the annulus. In this stage, the driller should keep the pressure at FCP. In this stage, casing pressure is dropped gradually as the new mud rises in the annulus. At the stage beginning, the forces acting in the annulus are the hydrostatic pressure in the downward direction and the pressure implemented by the pump in the upward direction. When the new mud enters the annulus and begins to rise upward, a new hydrostatic pressure implemented by the new mud will be applied in the downward direction. This new force that is implemented by the new mud decreases the summation of the forces in the upward direction in the annulus, thus the casing pressure gauge reading drops gradually as the new mud reaches the surface. 


\subsection{The engineer's method}

This method uses only one circulation to get rid of the kick and kill the well using the new mud directly. This well control method requires the new mud to be prepared and the ICP, FCP, and STB to be calculated before the operation is started. To understand the behavior of the pressures in the drill string and in the annulus, the circulation will be divided into two stages.

In the first stage of the circulation, the driller raises the pressure of the pump to ICP in order to implement enough pressure to combine with the hydrostatic pressure of the old mud for circulation and control the formation pressure. For mud circulation, the driller directly uses the new mud and this new mud will add a new hydrostatic pressure in the drill string (the new mud is heavier than the old mud), thus implement an additional hydrostatic pressure in the drill string, and to prevent any underground blowouts or generate a new kick, the driller must adjust the choke to decrease the pressure in the drill string gradually from ICP to FCP. This stage ends when the new mud reaches the bit.

In the second stage, the new mud begins to rise in the annulus leading to an increase in the hydrostatic pressure in the annulus. If kick type is water, as the hydrostatic pressure increases in the annulus, the summation of the forces of the pump pressure against the hydrostatic pressure will be decreased in the upward direction as described in the driller's method when the new mud raises in the annulus.

If the kick type is gas, the second stage will be divided into two parts. The first part begins when the mud begins to rise in the annulus and ends when the kick gets out of the well. In this part, the casing pressure begins to increase as the kick rises in the annulus because of the gas expansion in the annulus and cause a decrease in the hydrostatic pressure which control the formation pressure. It should be noted that the effect of the gas expansion lowering the total hydrostatic pressure is greater than the effect of the new mud. At the end of this part, the kick begins to get out of the well. As the low-density kick gets out of the well, the total hydrostatic pressure will depend only on the densities of the old mud and new mud and as a result, the total hydrostatic pressure will be raised. This increase the total hydrostatic pressure and affects the summation of the forces in the annulus negatively in the upward direction, thus the casing pressure reading will be dropped.

The second part begins when all of the gas kick gets out of the annulus. As the new mud with high density goes up in the annulus, the total hydrostatic pressure in the annulus will be increased, leading to decrease the casing pressure readings. 


\section{The result}

In this section, different kick problems will be simulated in the software during the normal drilling of real vertical wells case and different solving scenarios will be taken. For each case, the required calculations will be made to solve the problem and check whether our calculations solve the problem or not. Correct calculations with correct implementation can solve the problem properly, so using correct calculations and implement these calculations correctly in the software should also solve the simulated kick properly.

\section{Driller's method}

For this case the driller's method will be used. Table (1) lists the affected parameters before and after kick incidence that recorded using the program directly.

Table (1) Parameters before and after incidence (WQ2-372)

\begin{tabular}{|c|c|c|}
\hline Parameters & Before kick incidence & After kick incidence \\
\hline ROP & 23.8 & 78.8 \\
\hline Return flow & $45 \%$ & $65 \%$ \\
\hline P pump & 1063 & 788 \\
\hline Torque & 2836 & 3016 \\
\hline Mud tank & $79 \%$ & $84 \%$ \\
\hline
\end{tabular}

After kick incidence and BOP closing, the following parameters will be recorded: SIDDP is 481 psi, $\mathrm{SICP}$ is $546 \mathrm{psi}$, KRP is $476 \mathrm{psi}$ and SPM at kill rate pressure is $33 \mathrm{spm}$. Then calculate ICP:

$$
I C P=481+476=957 p s i
$$

Figure (1) shows a comparison between the theoretical accurate solution and the solution implemented by the user for the first circulation of this case. 


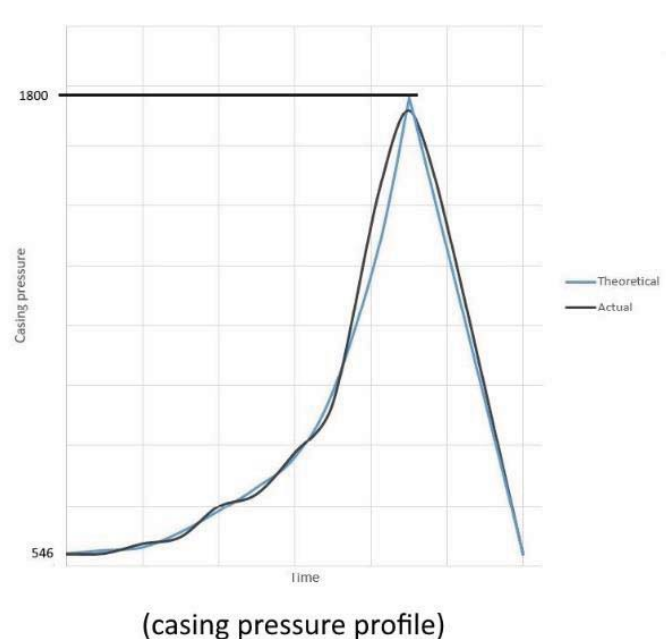

(casing pressure profile)

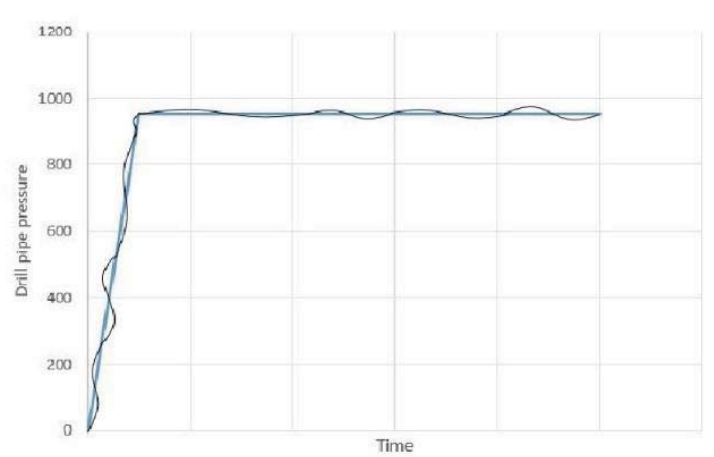

(Annular pressure profile)

Fig. (1) Pressure profiles (WQ2-372)

Despite of the differences between the theoretical solution and the implemented solution by the user, the implemented solution is considered as a correct solution as it is within the acceptable range.

Then we will go to the next step and make the required calculations:

$K M W=9.57+\frac{481}{0.052 * 5311}=11.31 p p g$

$S T B=\frac{5011 *\left(\frac{\pi}{4}\right) *\left(\frac{4.25}{12}\right)^{\wedge} 2+300 *\left(\frac{\pi}{4}\right) *\left(\frac{2.82}{12}\right)^{\wedge} 2}{0.117 * 5.615}=771 \mathrm{stk}$

$F C P=476 * \frac{11.31}{9.57}=563 p s i$

Figure (2) show a comparison between the theoretical accurate solution and the solution implemented by the user of the second circulation. 


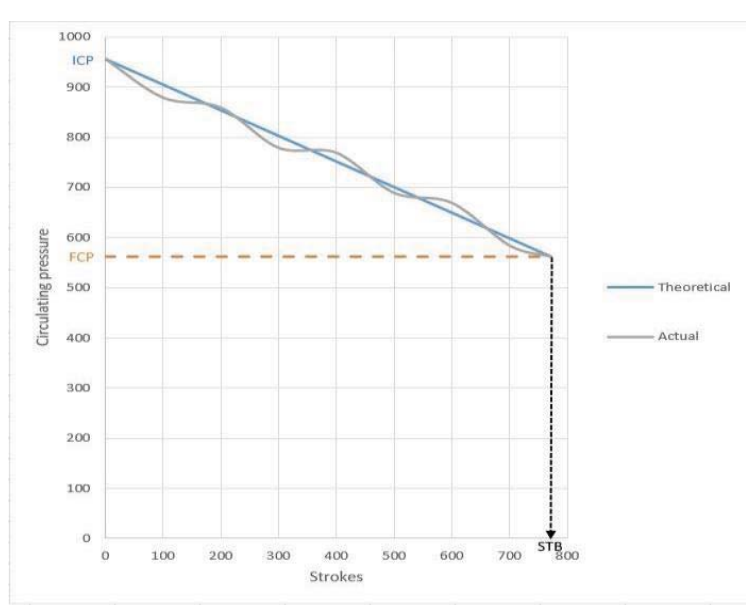

.Fig. (2) Circulating pressure profile from ICP to FCP

For the second circulation, the implemented solution is considered as a correct solution as it is within the acceptable range.

Based on the pressure profile in the annular in figure (1), the type of kick is gas. Water type kick can be solved using the same calculations and procedures used with gas kick.

\section{Engineer's method}

For this case, a kick will be made and then the engineer's method will be implemented. Table (2) lists the affected parameters before and after kick incidence that recorded using the program directly.

Table (2) Parameters before and after incidence (WQ2-372)

\begin{tabular}{|c|c|c|}
\hline Parameters & Before kick incidence & After kick incidence \\
\hline ROP & 19.6 & 75.2 \\
\hline Return flow & $46 \%$ & $73 \%$ \\
\hline P pump & 1119 & 743 \\
\hline Torque & 2326 & 3121 \\
\hline Mud tank & $77 \%$ & $86 \%$ \\
\hline
\end{tabular}

After kick incidence and BOP closing, the following parameters will be recorded: SIDDP is 472 psi, SICP is 529 psi and KRP is 544 psi. To achieve a correct solution, ICP, FCP, KMW and STB will be calculated and implemented:

$$
\begin{aligned}
& I C P=472+544=1016 \text { psi } \\
& K M W=9.62+\frac{472}{0.052 * 9345}=10.59 p p g
\end{aligned}
$$




$$
\begin{aligned}
& S T B=\frac{9045 *\left(\frac{\pi}{4}\right) *\left(\frac{4.25}{12}\right)^{\wedge} 2+300 *\left(\frac{\pi}{4}\right) *\left(\frac{2.82}{12}\right)^{\wedge} 2}{0.117 * 5.615}=1376 \mathrm{stk} \\
& F C P=544 * \frac{10.59}{9.62}=598 \mathrm{psi}
\end{aligned}
$$

Figure (3) shows the pressure profiles in the drill string and in the annulus, and shows a comparison between the theoretical accurate solution and the solution implemented by the user.

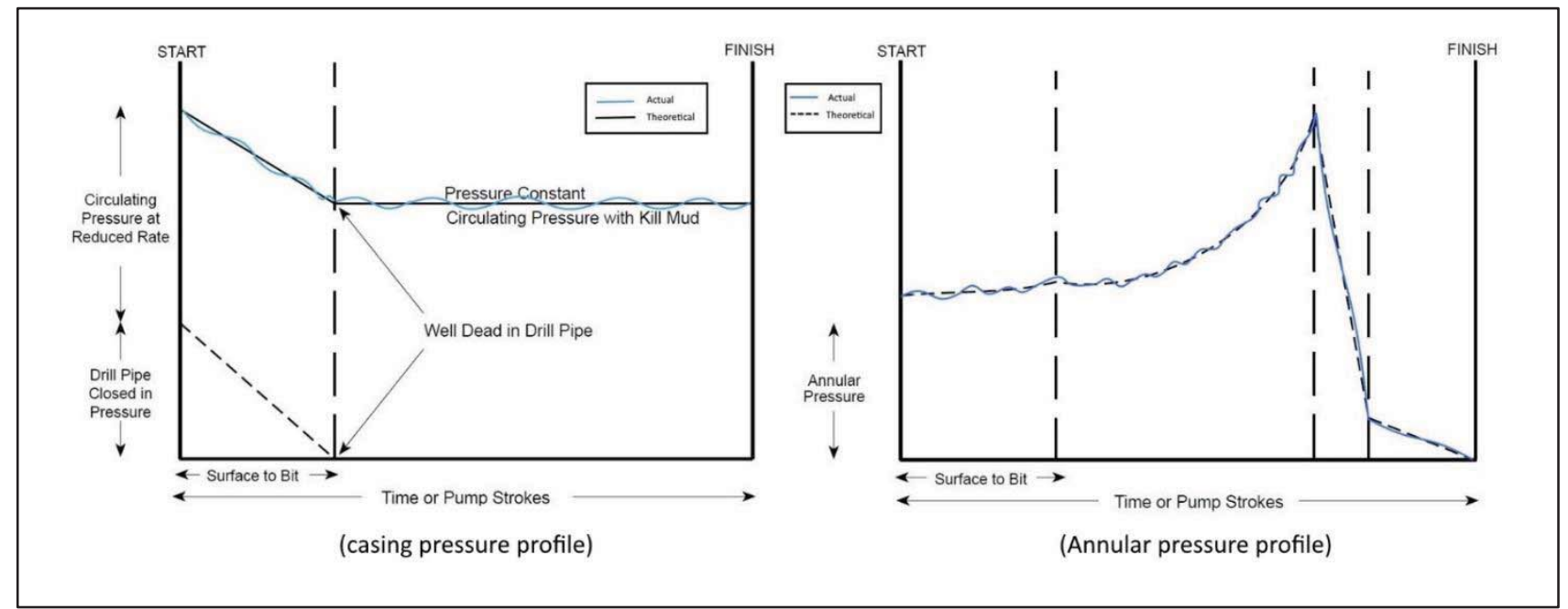

Fig. (3) Pressure profiles (WQ2-372)

The implemented solution is within the acceptable range and the operation is considered as a successful solution. The type of kick is gas and can be noted from the pressure profiles in figure (3). Water type kick can be solved using the same calculations and procedures used with gas kick, but during the first circulation a difference pressure behavior in the annulus will be noted. Figure (4) will be used to show the pressure profile in the annulus for the water kick type.

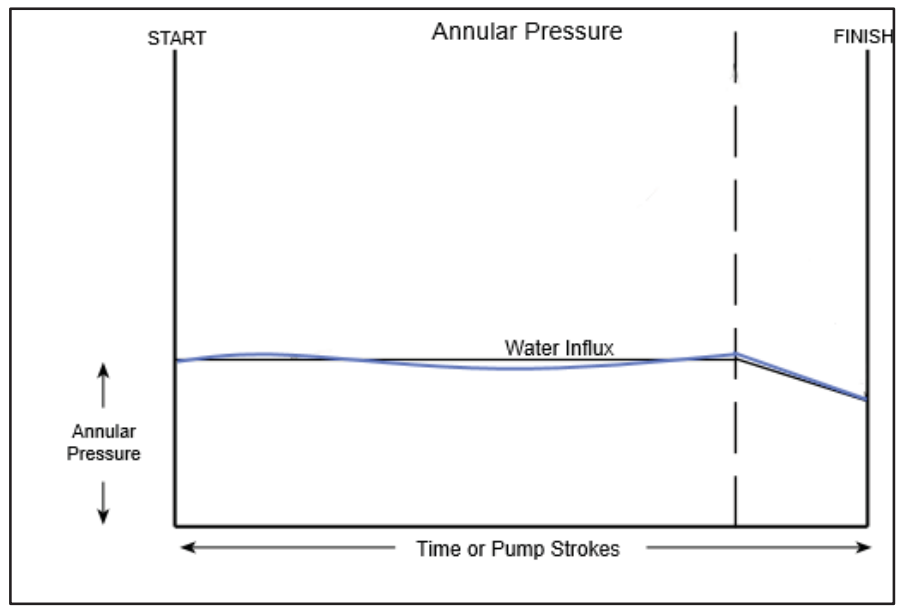

Fig. (4) Annular pressure profile for water kick (WQ2-372) 


\section{Incorrect calculation and incorrect implementation}

After we see how the simulation process goes using the correct calculations and the right procedures for driller's method and engineer's method, we will test how incorrect calculations and wrong procedures can be simulated through the solution procedures.

Two aspects of wrong decision will be tested in the program, using wrong solving inputs and improper use of choke equipment.

Wrong solving inputs with random values will be implement. The results of these inputs are presented in table (3).

Table (3) Different KMW and ICP scenarios with descriptions

\begin{tabular}{|c|c|c|c|}
\hline parameter & Correct & Used & Description \\
\hline \multirow[t]{4}{*}{ KMW } & 11.31 & 11.1 & $\begin{array}{l}\text { A new small kick to inter the annulus that make a miner effect on } \\
\text { casing pressure. }\end{array}$ \\
\hline & 11.31 & 10.5 & A new kick inters the annulus and can escalated to a blowout. \\
\hline & 11.31 & 11.4 & $\begin{array}{l}\text { An extra load is implemented by the used KMW on the } \\
\text { formation, but this extra load didn't exceed formation fracture } \\
\text { pressure. }\end{array}$ \\
\hline & 11.31 & 12 & $\begin{array}{l}12 \text { ppg implements an extra load on the formation and for this } \\
\text { case; this extra load exceeds formation fracture pressure and } \\
\text { cause an underground blowout. }\end{array}$ \\
\hline \multirow[t]{4}{*}{ ICP } & 957 & 900 & $\begin{array}{l}\text { a new small kick enters the well with small effect on casing } \\
\text { pressure. }\end{array}$ \\
\hline & 957 & 813 & a new kick inters the annulus and escalated to a blowout. \\
\hline & 957 & 970 & successful process. \\
\hline & 957 & 1450 & $\begin{array}{l}1450 \text { psi implements an extra load on the formation and cause an } \\
\text { underground blowout. }\end{array}$ \\
\hline
\end{tabular}

These random possibilities of ICP and KMW are tested using the engineer's method. These possibilities have the same result even with the driller's method.

FCP and STB values affect how the choke should be controlled. So we will implement a different choke control wrong possibilities and see the results. Firstly, we will present these possibilities using 
the driller's method. Figure (5) present a comparison between correct pressure profile and wrong pressure profile for two possibilities of driller's method first circulation, and shows the failure point for each possibility.

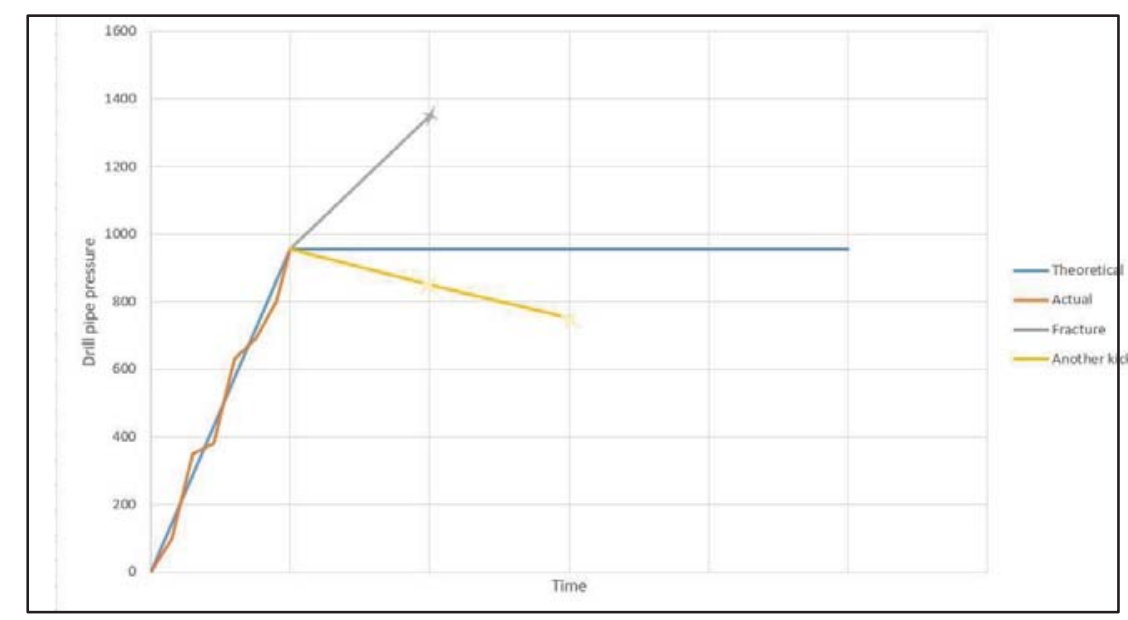

Fig. (5) Circulating pressure (fracture and new kick iterance scenarios)

The gray line represents the scenario when the user losses the control on the well, and this wrong control leads to make an underground blowout. The yellow line represents the scenario when the pressure in the well is decreased as a result of the wrong choke control made by the user and initiate a new kick which my escalated to a blowout.

Figure (6) present a comparison between correct pressure profile and wrong pressure profile for two possibilities of driller's method second circulation, and shows the failure point for each possibility.

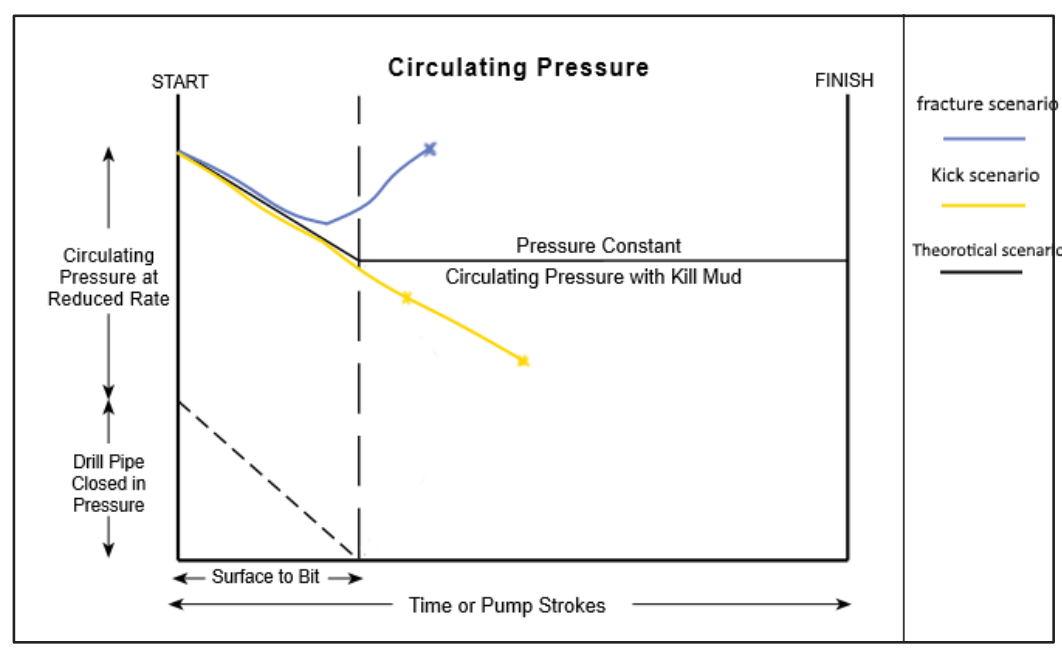

Fig. (6) Second circulation (different pressure profile scenarios) 
The blue line represents the scenario when an underground blowout is occurred because of the wrong choke control. The yellow line represents the scenario when the pressure in the well is decreased as a result of the wrong choke control made by the user and initiate a new kick as in the first cross within the line which my escalated to a blowout if the user continues the inappropriate choke control and decreases the pressure within the well.

\section{Conclusions}

1. A new software has been built successfully to simulate kick problems in vertical wells based on data and information that gathered from southern Iraqi fields.

2. The software includes both the driller's method and the engineer's method for well control.

3. The choke is the most difficult part in the simulation process and should be handled carefully.

4. The simulator include real cases of wells drilled in Basra, Nasiriya and Missan governorates.

5. Formations characteristics of southern Iraqi fields are taken into account while building the software.

$\begin{array}{llc}\text { Symbol } & \text { Description } & \text { Nomenclature } \\ \text { FCP } & \text { Final circulating pressure } & \text { Psi } \\ \mathrm{h} & \text { Height } & \mathrm{Ft} \\ \mathrm{ICP} & \text { Initial circulating pressure } & \text { Psi } \\ \text { KMW } & \text { Kill mud weight } & \text { Psi } \\ \text { PH } & \text { Hydrostatic pressure } & \text { Psi } \\ \text { SICP } & \text { Shut in casing pressure } & \text { Psi } \\ \text { SIDPP } & \text { Shut in drill pipe pressure } & \text { Psi } \\ \text { TVD } & \text { True vertical depth } & \text { Ft } \\ \rho \text { influx } & \text { Influx density } & \text { Ppg } \\ \rho \text { mud } & \text { Mud density } & \text { Ppz }\end{array}$




\section{$\underline{\text { References }}$}

1. M. a.-J. D. A.-S. W.J. Mohammed, "Reservoir Flow Simulation Study for a Sector in Main Pay-South Rumaila Oil Field," in SPE Oil and Gas Conference and Exhibition, Mumbai, 2010.

2."Hydrocarbons technology," Kable, 2017. [Online]. Available: http://www.hydrocarbonstechnology.com.

3. L. A.-H. H. Q. Sami El-Halfawi, "Achieving Excellence in Well Completion Projects in Iraq's South Oil Fields," in SPE/IADC, 2011.

4. M. P. S. A. a. D. M. Anastasia Vedernikova, "Overcoming Challenges in the West Qurna-2 Drilling Campaign," in SPE/IADC, 2016.

5. H. A. Flayeh, Re-evaluation of Logs in Nasiriyah Oil Field For the Discovery of By Passed Oil Zones Thesis, Baghdad: University of Baghdad/College of Engineering/Department of Petroleum Engineering, 2013.

6. Z. M. a. A. F.H.M.Ali, "Microfacies Analysis and Reservoir Characterisation of Late Cenomanian to Early Turonian Mishrif Reservoirs, Garraf Field, Iraq," in IPTC, 2013.

7. H. S. a. W. A. Sammarrai, "Designing and Implementing a Competency-based Development Program for Iraqi Graduate Engineers," in SPE, Amsterdam, 2014.

8. H. Imad, Building a Geological Model for the Buzurgan Oil Field / Mishrif Formation, Baghdad: University of Baghdad, 2012.

9. A. A. Abdullah, Geostatistical Study of Mishrif Reservoir in Noor Oil Field Thesis, Baghdad: University of Baghdad/College of Engineering/Department of Petroleum Engineering, 2014.

10. A. Awni, Variation of Petrophysical Properties in Abughirab and Fauqi Oil Fields/ Asmari Reservoir Thesis, Baghdad: University of Baghdad/College of Engineering/Petroleum Engineering Department, 2012. 